Pecvnia, 1 (2005), pp. 93-124

\title{
Reflexiones sobre la naturaleza y los orígenes de la contabilidad por partida doble
}

\author{
Esteban Hernández Esteve
}

Este trabajo tiene por objeto exponer algunas reflexiones personales del autor sobre la naturaleza y los orígenes de la contabilidad por partida doble. Se ha escrito y discutido mucho sobre esta cuestión, pero no parece que se haya llegado a conclusiones claras y terminantes. Así, al hablar de su naturaleza se mezclan conceptos, requisitos formales e instrumentos, formando un totum revolutum. Por otra parte, al tiempo que se esgrimen como definitorios los requisitos y características explicados por Luca Pacioli en su Tractatus Particularis de Computis et Scripturis, se acepta generalmente que la contabilidad por partida doble surgió en algún momento del siglo XIII, y se afirma que, en cualquier caso, la primera contabilidad llevada con certeza por partida doble fue la de los Massari de Génova en 1340. Sin embargo, Pacioli prescribe que la partida doble debe llevarse mediante dos libros, el Diario y el Mayor, y el primer Libro Diario conocido es el de Andrea Barbarigo del año 1430. No se han encontrado
This paper intends to expose some personal reflections of the author on the nature and the origins of double-entry accounting. It has been written and discussed a lot on this item, but it does not seem that clear and final conclusions have been reached. When speaking of its nature, concepts, formal requirements and instruments are mixed, forming a totum revolutum. On the other hand, at the same time as the requirements and characteristics explained by Luca Pacioli in his Tractatus Particularis de Computis et Scripturis are considered as distinctive features of doubleentry accounting, it is generally accepted that this system arose at some moment of $13^{\text {th }}$ century, and further affirmed that, in any case, the first accounting kept with certainty by double-entry was the one of the Massari of Genoa in 1340. Nevertheless, Pacioli prescribes that double-entry must be kept by means of two books, the Journal and the Ledger. The first known Journal is that of Andrea Barbarigo of year 1430. No previous Journals have been found, nor it seems that they have 
Diarios de fecha anterior, ni parece que hubieran existido desde muchos años antes $\mathrm{y}$, ciertamente, los Massari no llevaban Libro Diario. Todos estos hechos le inducen al autor a preguntarse si no es tiempo ya de plantearse una reconsideración general del tema. Entre tanto llega ésta, el autor se permite resumir, provisionalmente y sin ánimo de exhaustividad, las principales condiciones que a su juicio definen y caracterizan la naturaleza y la práctica de la contabilidad por partida doble.

Palabras clave: Historia de la contabilidad, orígenes de la contabilidad por partida doble, libros de cuentas, contabilidad medieval. existed, at least not since many years before. In any case, the Massari did certainly not keep a Journal. All these facts induce the author to ask himself whether it is not already time to make a general reconsideration of the subject. While this reconsideration arrives, the author does allow himself to summarize, provisionally and without any spirit of exhaustiveness, the main conditions that in his opinion define and characterize the nature and the practice of the double-entry accounting.

Key words: Accounting history, origin of doubleentry accounting, account books, medieval accounting.

\section{INTRODUCCIÓN: NATURALEZA Y CARACTERÍSTICAS DE LA PARTIDA DOBLE. ALGUNAS OPINIONES AUTORIZADAS \\ El tema de la naturaleza y orígenes de la contabilidad por} partida doble ha sido una de las cuestiones más debatidas y estudiadas desde los inicios del interés por conocer la historia de la disciplina, allá por la postrimerías del siglo XIX, hasta bien entrado el último tercio del siglo XX. Todavía hoy se siguen produciendo algunos trabajos sobre el tema, a pesar de que la hegemonía del mundo anglosajón en materia histórico-contable y la aparición en su seno de la "nueva historia de la contabilidad", con su predilección por la utilización de planteamientos y teorías sociológicas para explicar los acontecimientos, ha contribuido a quitar actualidad y prestigio a este tipo de investigaciones de marcado carácter técnico, en las que dado el escaso desarrollo económico de la época estudiada resulta difícil encontrar a los hechos y a su evolución las motivaciones de búsqueda de dominio, explotación y disciplinamiento social $\tan$ en boga hoy día, aunque realmente no dejarían de estar presentes y coactuar de una forma u otra en buena parte de los casos, pues el deseo de autoafirmación, que se traduce normalmente en una merma de la posición relativa de las personas del entorno, es connatural en el género humano y no sólo desde que se descubrió la lucha de clases.

En cierto sentido, es una pena que la discusión sobre la naturaleza y los orígenes de la partida doble haya perdido actualidad, porque, a pesar de lo mucho que se ha escrito y discutido sobre esta cuestión, lo cierto es que no se ha llegado todavía a ninguna conclusión 
precisa y terminante. Falta para ello, en primer lugar, una definición clara y terminante de la naturaleza de la partida doble, con enunciación de los requisitos que debe necesariamente cumplir: careciendo de esta definición y de esta enunciación, es claro que la cuestión de sus orígenes resulta inconcreta e indeterminada.

A este respecto, debe señalarse que una de las definiciones más completas, solventes y aceptadas de la contabilidad por partida doble fue la formulada por Raymond de Roover en su conocido artículo "Aux origines d'une technique intellectuelle. La formation et l'expansion de la comptabilité à partie double", publicado en el volumen IX, año 1937, de Annales d'Histoire Economique et Sociale. Este artículo marcó el comienzo de una nueva etapa en el estudio de la historia de la contabilidad, constituyendo la primera aproximación científica a esta disciplina. No es casualidad que dicho trabajo apareciera en la innovadora revista de Marc Bloch y Lucien Febvre, creada en 1929, que vino a revolucionar el objeto de estudio y la forma de entender la historia económica y social, hasta el punto de que el enfoque propugnado por los Annales fue llamado por su promotores "la nouvelle histoire", en un anticipo de más de cincuenta años a lo que luego habría de suceder, en un campo más restringido, con la "nueva historia de la contabilidad".

Para Raymond de Roover, "la contabilidad por partida doble debe su nombre al hecho de que cada asiento del Diario da lugar a la inscripción de dos partidas o asientos en el libro Mayor, una de ellas al Debe y la otra al Haber. Pero, esta condición no es suficiente por sí misma: es necesario también que el importe asentado en el Debe sea igual que el asentado en el Haber y que todas las cantidades estén expresadas en la misma unidad monetaria que sirva de medida común. En consecuencia, cuando se sume el Debe y el Haber del Libro Mayor, los totales deberán ser necesariamente iguales, si las anotaciones han sido efectuadas con exactitud" (Roover 1937: 270).

La observación integral y rigurosa del principio de la dualidad de las anotaciones en el Libro Mayor es para Roover una condición sine qua non. Si no se da, no existe contabilidad por partida doble. No basta, por consiguiente, con que las cuentas se presenten en dos columnas, una para el Debe y otra para el Haber. En efecto, aunque las contabilidades por partida doble se presenten de esta manera, para averiguar si una contabilidad está llevada por este método, deberá comprobarse cuidadosamente que cada partida del Debe tiene una contrapartida en el Haber y viceversa. 
Otra característica esencial de la partida doble consiste, para Raymond de Roover, en el hecho de que el Libro Mayor contenga un juego completo de cuentas, es decir, tanto cuentas impersonales como cuentas personales. Asimismo, para que la contabilidad sea completa será necesario igualmente que existan cuentas de resultados que recojan los aumentos o disminuciones de valor surgidos como consecuencia del ejercicio comercial. Del mismo modo, deberán existir cuentas de gastos donde se anoten los que deban realizarse en el desarrollo del comercio. Finalmente, toda empresa exige una aportación de fondos. Por ello, será necesario abrir una cuenta de capital que represente los capitales invertidos en el negocio, cuyo saldo constituirá la contrapartida del excedente del Activo sobre el Pasivo.

En resumen, Raymond de Roover distingue a estos efectos cinco categorías de cuentas: cuentas de personas, de valores, de gastos, de resultados y de capital. Estas cuentas se encuentran en toda contabilidad por partida doble formando un juego completo en el que todas las partidas se engarzan perfectamente las unas con las otras y dan lugar al balance, que refleja el equilibrio entre el Activo y el Pasivo, sintetizando los resultados. Añade Roover que el principio de dualidad no es una convención, sino que responde a la realidad de los hechos, pues consistiendo el comercio en un intercambio de bienes, toda prestación comporta necesariamente una contraprestación.

Mientras la partida simple, en la que sólo ciertas operaciones son contabilizadas, no puede proporcionar más que una información parcial, el método de la partida doble suministra un información completa.

Debe destacarse que, como se habrá observado, Raymond de Roover une indisolublemente la contabilidad por partida doble al ejercicio del comercio: para él, la partida doble es la contabilidad de los comerciantes, una circunstancia que no es ciertamente consustancial, como hoy día reconoce prácticamente la generalidad de los historiadores.

Sintetizando, de acuerdo con lo expuesto anteriormente, los requisitos que Raymond de Roover considera necesarios para que una contabilidad pueda considerarse llevada por partida doble son los siguientes:

1. Dualidad de anotaciones. Cada asiento en el Debe del Libro Mayor debe tener una contrapartida por el mismo importe en el Haber.

2. Todos los importes asentados en el Libro Mayor deben estar expresados en la misma unidad monetaria. 
3. En consecuencia, las sumas totales del Debe y del Haber del Libro Mayor deben ser necesariamente iguales.

4. Las cuentas del Libro Mayor se presentan divididas en dos columnas, una para el Debe y otra para el Haber.

5. El Libro Mayor debe contener un juego completo de cuentas, es decir, compuestas por cinco clases de cuentas: cuentas de personas, de valores, de gastos, de resultados y de capital.

6. Todas las operaciones realizadas por el dueño de los libros deben ser contabilizadas, circunstancia permitida por la existencia de estas cinco clases de cuentas.

7. De este modo, estas cuentas, que se engarzan y encajan perfectamente unas con otras, proporcionan una información completa sobre las actividades comerciales del dueño de la contabilidad.

8. Las mismas dan lugar a la formación de un balance, reflejo del equilibrio entre Activo y Pasivo y síntesis de los resultados.

Fabio Besta, en el tomo tercero de su monumental obra La Ragioneria, aunque sin relacionarlas formalmente, ya había hecho referencia a algunas de estas condiciones:

1. Dualidad de las anotaciones en el Debe y en el Haber.

2. Cuentas dispuestas formalmente en dos secciones contrapuestas.

3. Una sola moneda de cuenta.

4. Referencia inexcusable a la cuenta de contrapartida.

5. Existencia de dos series completas de cuentas antitéticas: las cuentas de los elementos reales, es decir, de cuentas de la primera serie como hoy día se denominan habitualmente en Italia, y las cuentas derivadas, o de la serie segunda, que es la denominación que se da en ese país a las cuentas de neto. La partida doble se obtiene de la antítesis entre las cuentas de los elementos reales y las cuentas derivadas: en las primeras las modificaciones activas se registran en el Debe y las modificaciones pasivas en el Haber, mientras en las cuentas derivadas las mutaciones activas se registran en el Haber y las pasivas en el Debe. 
Como puede apreciarse, en cierta manera Raymond de Roover alivia el carácter formal de los requisitos previstos por Besta para que una contabilidad pudiera considerarse llevada por partida doble.

Pero, quien realmente los aligeró de forma considerable fue Federigo Melis. En efecto, a este autor, que posteriormente logró fama y reconocimiento como historiador económico, pero que no ejerció nunca una actividad propiamente contable, su maestro Della Penna, inmediatamente después de que hubiera obtenido la licenciatura en la Facultad de Economía y Comercio de la Universidad de Roma, le encargó la enseñanza de la historia de la contabilidad. En el desempeño de esta enseñanza Melis se propuso demostrar en su libro Storia della Ragioneria, que comenzó a escribir en seguida, que la partida doble tuvo su origen en la Toscana, su región natal. Pero tuvo que interrumpir sus estudios, porque fue llamado a las armas como consecuencia de la segunda guerra mundial. Hecho prisionero y llevado a Sudáfrica, no pudo regresar a Roma hasta 1945. Retomó entonces la enseñanza y terminó su libro, que fue publicado en 1950, cuando apenas tenía 35 años.

Fiel a su propósito, como en la Toscana las cuentas se llevaban en un principio por la modalidad de secciones sobrepuestas, descalificó las tesis de Besta y de Raymond de Roover, comentando que la forma en que las cuentas estuvieran dispuestas no determinaba en absoluto si las anotaciones estaban hechas en partida doble o no:

Se presente la cuenta en secciones una encima de la otra, o ubicadas o distribuidas en zonas diferentes del libro, o incluso diseminadas en libros distintos, con tal de que estén individualizadas en su signo y en el objeto de variación..., lo esencial es que la cuenta haya sido concebida de forma que permita la consecución del objetivo del método (Melis 1962: 391 ss.)

Previamente había definido la partida doble diciendo que es:

un método contable que basándose en la doble consideración analítica y unitaria de la riqueza con la que trata la hacienda, la traduce en dos series de cuentas (como derivación directa de tales aspectos) y para cada hecho económico la expresa invariablemente en dos distintos asientos, de igual valor y antitéticos en su signo (Debe y Haber).

Por otra parte, dado que en Florencia se utilizaban distintas clases de monedas, también la unidad de cuenta única es para Melis un 
factor totalmente irrelevante: "lo que cuenta no es la igualación inmediata de los valores bajo los signos contables unitarios, sino su equivalencia".

Como en la contabilidad toscana medieval se omitía muy a menudo la referencia a la cuenta de contrapartida, Melis sostuvo siempre que esto era un elemento puramente formal; lo importante era que, si se buscaba, la contrapartida existiese. Pero, al hacer esta afirmación, no paraba mientes en que una contrapartida sólo es tal si se demuestra su conexión con la partida correspondiente, de signo contrario.

A este respecto, Melis ni siquiera consideraba necesario que la partida estuviera asentada en el Libro Mayor con la misma fecha que la contrapartida. Es importante recordar en este sentido, como hace Antinori, que en la Edad Media, antes del establecimiento de la partida doble, no se hacía constar la fecha en los asientos (2003: 25).

En definitiva, según Federico Melis, aparte de la dualidad de anotaciones, la única condición verdaderamente válida para determinar la existencia de la partida doble era la presencia de las cuentas de neto "introducidas en el método nuevo".

Todos estos planteamientos de Melis, con sus puntos débiles y sus motivaciones interesadas, han sido muy bien explicados recientemente por Carlo Antinori, uno de los grandes especialistas mundiales en Luca Pacioli y la contabilidad medieval italiana, en sendas conferencias dictadas en España los años 2001 y 2003.

Para Carlo Antinori la mejor forma de conocer las reglas y requisitos de la contabilidad por partida doble es atenerse a lo que Luca Pacioli indica en el Tractatus XI Particularis de Computis et Scripturis de su obra Summa de Arithmetica, Geometria, Proportioni et Proporcionalita, (Pacioli 1994). Pacioli, que publicó en Venecia el año 1494 la primera exposición impresa de la contabilidad por partida doble, explicándola de forma detallada y completa, recoge en su obra la forma en que se aplicaba y enseñaba en el siglo XV el método de la partida doble, qué reglas debían ser observadas en su aplicación, y a qué grado de perfección habían llegado los contables del siglo XV en su desarrollo. Para Carlo Antinori, atenerse a las explicaciones de Pacioli significa establecer un punto de referencia incontrovertible, indiscutible, que está por encima de los chovinismos de todos los historiadores que se han ocupado de la materia (Antinori 2001: 21). 
De acuerdo con Antinori, éstas son, en síntesis, las principales reglas del "método" aplicadas y enseñadas en Venecia en el siglo $\mathrm{XV}$, con casi seguridad ya desde los primeros años del siglo, tal y como las refleja Luca Pacioli en su Tractatus XI, capítulo 36, folio 209 v $^{\circ}$ :

$\underline{\text { Sumario de reglas y maneras de llevar un libro de mercaderes }}$

1. Tienes que asentar en el Mayor todos los acreedores a mano derecha y los deudores a mano izquierda.

2. Todas las partidas que pases al Mayor tienen que ser dobles, es decir, si haces a alguien acreedor, habrás de hacer también deudor a alguien.

3. Todas las partidas, tanto las del Debe, como las del Haber, deben contener tres cosas: día del pago, importe del pago y razón del pago.

4. El mismo día en que se escribe la partida del Debe, tiene que escribirse la partida del Haber.

5. Conviene que la columna de cantidades del Mayor se refiera siempre a la misma moneda, aunque en el texto del asiento pueden consignarse las monedas que realmente hubieran intervenido en la operación, bien fueran ducados, liras, florines, escudos de oro o la moneda de que se tratase.

6. De este modo, al sacar los importes a la columna de cantidades, conviene que vayan todos en la misma moneda en que comenzaste el Mayor.

Estas son, pues, para Carlo Antinori las auténticas condiciones que, en síntesis, debe cumplir una contabilidad para poder ser considerada como de partida doble: las recogidas por Luca Pacioli en su famosa obra.

De la simple exposición de cuatro o cinco de las opiniones más cualificadas sobre lo que constituye la esencia de la contabilidad por partida doble, las del propio Luca Pacioli, de Fabio Besta, Raymond de Roover, Federico Melis y Carlo Antinori, se infiere que, como se decía al principio, la cuestión está todavía en espera de un proceso de definición y clarificación. En efecto, las condiciones y explicaciones que se proponen sobre lo que constituye la naturaleza de la partida doble son, en realidad, una mezcla de requisitos formales, conceptos y prácticas que se ofrecen 
formando un totum revolutum sin separación de alcances y cometidos. Parece, por consiguiente, que sí caben y, aun, se precisan ulteriores tratamientos del tema.

No es propósito de estas líneas presentar un tratamiento erudito en este sentido. No; el objetivo es mucho más modesto y limitado. Se circunscribe, simplemente, a mi deseo de pensar en voz alta, de expresar algunos pensamientos y reflexiones sobre el tema que desde hace algún tiempo me vienen rondando por la cabeza y que tal vez, pero sólo tal vez, algún día, si se formalizan y adquieren una hechura clara, puedan presentarse con un carácter más estructurado y académico.

\section{IMPORTANCIA Y ORÍGENES DE LA CONTABILIDAD}

Como ya he dicho en alguna que otra ocasión, la contabilidad, es decir, el arte de tener cuenta y razón, o sea, "lo que se requiere en toda cosa", como la definían nuestros antiguos autores castellanos (Covarrubias 1987: 352), es una actividad tan antigua como la propia Humanidad. En efecto, desde que el hombre es hombre, y aun mucho antes de conocer la escritura, ha necesitado llevar cuentas, guardar memoria y dejar constancia de datos relativos a su vida económica y a su patrimonio: bienes que recolectaba, cazaba, elaboraba, consumía y poseía; bienes que almacenaba; bienes que prestaba o enajenaba; bienes que daba en administración; etc.

Recientes investigaciones como las de la arqueóloga Denise Schmandt-Besserat (1978; 1980; 1981a; 1981b; 1983; 1984a; 1984b; 1986a; 1986b, 1988, 1992a y 1992b), comentadas y profundizadas en los aspectos contables por Richard Mattessich (1987; 1988; 1994 y 1996), han mostrado cómo los antiguos mesopotamios, ya hace 8.000 años, mucho antes por consiguiente de la invención de la escritura, llevaban las cuentas de sus bienes por medio de bolas de arcilla en las que introducían piedrecillas a las que se asignaba un valor simbólico. Por otra parte, es bien conocido el uso de tarjas, o palos de caña o de madera, de las que hasta hace bien poco se servían todavía algunos lugareños para llevar y justificar determinadas cuentas, así como también el empleo de sistemas a base de cuerdas con nudos utilizados, asimismo, para llevar cuentas sin necesidad de usar la escritura.

Por otra parte, las modernas investigaciones de arqueólogos e historiadores de la Antigüedad especializados en la historia de Mesopotamia, 
tales como Hans Nissen, Peter Damerow y Robert Englund (1990), que empalman con las del investigador, también alemán, A. Falkenstein (1964), permiten afirmar que los primeros documentos escritos que se conocen, constituidos por millares de tablillas de arcilla con inscripciones en caracteres protocuneiformes, elaboradas a finales del cuarto milenio antes de Jesucristo, es decir, hace más de 5.000 años, contienen tan sólo números y cuentas. Este hecho hace concluir a los indicados investigadores que la escritura debió de surgir, hacia el año 3300 a.J., como consecuencia precisamente de la necesidad que sentían los antiguos habitantes de Mesopotamia de registrar y dejar constancia de sus cuentas. A este objeto, instrumentaron unos sistemas numéricos ad hoc que Nissen y sus colaboradores han conseguido descifrar y explicar. No fue, pues, el deseo de legar a la posterioridad el recuerdo de hazañas guerreras, relatos de héroes o dioses, o de plasmar normas jurídicas para su permanente constancia y cumplimiento, lo que motivó el nacimiento de la escritura, como se creía y explicaba hasta ahora, sino simple y llanamente la necesidad de recoger y conservar las cuentas originadas como consecuencia de procesos productivos y administrativos. A la contabilidad se debe, pues, según estos investigadores, la invención de la escritura.

Realmente, a poco que nos detengamos a pensar en ello, nos percataremos de que la necesidad de llevar cuentas se extiende a todas las actividades humanas que tengan una vertiente económica y manejen magnitudes mensurables que deban ser recordadas y tomadas en consideración. De acuerdo con esta necesidad generalizada, los motivos y las razones por los cuales se llevan cuentas han sido desde siempre muy variados y dispares, pero los historiadores haciendo un esfuerzo de sistematización han procurado reducirlos a dos fundamentales y primarios: en primer lugar, la necesidad por parte de agentes, factores y administradores de rendir cuentas de su gestión a sus principales $\mathrm{y}$, en segundo, la necesidad sentida por comerciantes, empresarios y unidades económicas en general de conocer el importe de sus créditos y obligaciones en relación con sus deudores y acreedores, respectivamente, un conocimiento que más tarde quiso extenderse a la marcha de sus actividades y de los elementos patrimoniales en su totalidad. En principio puede parecer que ambas motivaciones son similares e indiferentes, pero lo cierto es que, según la motivación primaria que se quisiera satisfacer, el desarrollo de las anotaciones contables adoptó unas características específicas, que se fueron plasmando en dos sistemas distintos de contabilidad. Así, la primera motivación dio lugar a lo que en España se 
conoce como método de "Cargo y Data", o también "libro de pliego horadado", atendiendo a la forma de conservar los pliegos sueltos en que se llevaba dicha contabilidad. A este método Diego del Castillo lo llama de "Cargo y Descargo", pues en él se hace "cargo al administrador de todo lo que recibió, y recibiéndole en descargo, todo lo que dio y gastó". Para Castillo esta forma es la más grosera de las tres que enuncia (Castillo 1522: folio III $v^{\circ}$ ), encuadrándose las otras dos dentro de la segunda motivación. En efecto, ésta, en cambio, produjo a través de aproximaciones sucesivas, primero, anotaciones en el libro de "Data y Recibo", como lo llama Castillo, comentando que "los mercaderes y personas que tienen cuenta con otros, asientan en sus libros, en una parte el recibo, y en otra parte lo que dan. Y cuando averiguan sus cuentas unos con otros, entran por Data y Recibo". Posteriormente, las anotaciones fueron evolucionando hasta llegar finalmente al descubrimiento de la partida doble. A este método lo llama Diego del Castillo "Debe y Debe haber", aunque generalmente se lo llamaba en Castilla en esos primeros tiempos método del "Debe y Ha de haber" o del "Libro de Caxa con su Manual". Sobre este método de la partida doble Castillo comenta lo siguiente: "Otros asientan en una plana lo que deben, y en otra plana lo que deben de haber, y cuando hacen cuentas, entran con debe y debe haber". Bartolomé Salvador de Solórzano, autor del primer libro sobre contabilidad por partida doble publicado por un español, hace también referencia al método de pliego horadado, comentando que los hombres "dieron al principio en tener esta cuenta y razón por diferentes modos, unos en libro de pliego horadado, y otros en libros encuadernados comunes y ordinarios, y otros en papeles sueltos, y aunque por aquel camino se tenía la cuenta y razón de lo que pretendían, por otra parte hallaban que por él no se podían averiguar las cuentas que con otras personas tenían, ni se podía ver lo que los dueños de los dichos libros debían, ni lo que a ellos se les debía, si no era con mucho trabajo y prolijidad; y para el remedio de ello les fue forzoso inventar (como inventaron) dos libros intitulados, el uno de Caxa, y el otro su Manual", es decir, la contabilidad por partida doble (Salvador 1590: Prólogo).

Sea como fuere, los planteamientos contables que respondían a ambas motivaciones convivieron en paralelo, conservando sus enfoques peculiares, hasta que la invención de la contabilidad por partida doble, global, omnicomprensiva y perfectamente interrelacionada, vino a asumirlos a ambos y a satisfacer a la vez las dos motivaciones primarias, aunque el método de Cargo y Data sobrevivió durante siglos como sistema propio de la Administración pública y de las entidades sin ánimo de lucro, como en seguida se verá. 


\section{PRIMEROS TIEMPOS DE LA CONTABILIDAD}

Como se ha anticipado ya, las anotaciones contables se diferenciaron desde un principio al objeto de adaptarse a las dos finalidades fundamentales a que obedecían: primera, la de satisfacer la obligación de agentes y factores de rendir cuentas a sus principales acerca de la gestión de los bienes y haciendas confiados a su cuidado, y, segunda, la de seguir de cerca la marcha global de los propios negocios o actividades. Aunque con numerosos puntos de contacto y solapamiento, ambas finalidades dieron lugar en principio a dos distintos sistemas de registro contable, con características propias y específicas.

En el primer caso, la contabilidad estaba destinada a registrar relaciones de tipo bilateral entre dos personas, el factor o agente y su principal, con el fin de reflejar en cada momento la situación deudora o acreedora de aquél con respecto a éste. Esta situación era consecuencia de las transacciones realizadas entre las dos partes, así como de las operaciones llevadas a cabo por el agente con terceras personas por cuenta de su principal en el ejercicio normal de la gestión encomendada. A estos efectos, se llevaba cuenta y razón de los bienes o dineros que el agente recibía de su principal o por su cuenta, así como de los desembolsos que efectuaba en nombre y por cuenta de éste. La característica esencial de este sistema de registro contable es que no toma para nada en consideración el patrimonio del dueño de los libros, sino solamente la relación de éste con uno o varios agentes, considerados uno a uno. Nos han llegado ejemplos de este tipo de contabilidad de los tiempos más remotos. De este modo, conocemos cuentas de administradores de la antigua Mesopotamia, de la China del tercer milenio antes de Jesucristo, de la Grecia del siglo IV también antes de Jesucristo, del Egipto del siglo I de nuestra era y de la Roma de esa misma época, etc.

Esta clase de contabilidad fue, por otra parte, la desarrollada por las Administraciones públicas. En efecto, su planteamiento se ajustaba a la necesidad de controlar la actuación de los funcionarios y de las personas a las que se encomendaba una misión que involucrase la recepción, entrega y manejo de los dineros o bienes públicos. En los reinos de Castilla, estas prácticas contables originaron, ya avanzada la Edad Media, el llamado sistema de Cargo y Data. En este sistema, se abría una cuenta a cada persona encargada de un cometido que implicase la movilización de caudales públicos, bien para recibirlos, bien para gastarlos o para ambas cosas a la vez. Cada cuenta estaba compuesta por dos partes, el Cargo y la Data, que se llevaban por separado, una después 
de la otra. El Cargo recogía por orden cronológico todas las cantidades de dinero y de bienes recibidas por el titular de la cuenta en nombre de la Administración: era su Debe, es decir, lo que se le cargaba y lo que él adeudaba a la Administración. La Data, que se llevaba a continuación, recogía, por el contrario, las cantidades que el titular pagaba o entregaba por cuenta de la Administración: era su Haber, lo que se le abonaba, descargaba o acreditaba. Cuando se cerraba la cuenta, en el folio final de la misma se consignaban las sumas de todas las partidas del Cargo y de la Data, sacándose a renglón seguido el saldo o alcance, que podía ser a favor de la Administración, como era lo corriente, o del titular de la cuenta. Estas dos secciones, lados o signos contables, Cargo y Data, o lo que es lo mismo, Debe y Haber, son, dicho sea de paso, las dos secciones tradicionales de la contabilidad, cuyas denominaciones encontramos ya entre los romanos. En torno a estas cuentas personales que constituían el núcleo del sistema contable, se instrumentaba una abigarrada constelación de registros auxiliares para llevar memoria de aspectos complementarios. Este mismo sistema de Cargo y Data era, por otra parte, el seguido por el resto de las Administraciones públicas europeas, con uno u otro nombre. En la Administración pública castellana, sin embargo, presentaba una característica curiosa: la de que las cuentas eran llevadas en pliegos sueltos agujereados. Al ser llevadas en pliegos sueltos, todas las cuentas podían ser agrupadas en un solo libro ordenadas alfabéticamente, ya que cuando era necesario, bien porque los pliegos de una cuenta se hubieran completado, bien porque hubiera que abrir una cuenta nueva, podían insertarse nuevos pliegos en el lugar correspondiente. La agrupación se conseguía haciendo un agujero en la esquina superior izquierda de los pliegos, por donde se pasaba un cordón o una cinta para unirlos a todos formando un libro. Tal práctica motivó que al sistema contable de Cargo y Data se lo conociera en Castilla también con el nombre de método o libro del pliego horadado, como ya se ha señalado.

Por lo que respecta a la segunda modalidad de registros contables, es decir, los destinados a facilitar una visión de la marcha de los negocios y actividades llevados a cabo por explotaciones, mercaderes, empresas y unidades económicas en general, debe decirse que surgieron también en los tiempos más remotos. A este respecto se conocen ejemplos de cuentas de explotaciones ganaderas y agrícolas mesopotámicas del tercer milenio antes de Jesucristo. En un principio, parece que esta clase de anotaciones debió de surgir de la voluntad de registrar la situación financiera del dueño de los libros con respecto a terceras personas, es 
decir, sus deudores y acreedores, pero en seguida trascendió de este objetivo para intentar reflejar de manera más amplia la situación del patrimonio y los negocios del mismo. Mientras la modalidad anterior, es decir, la destinada a registrar relaciones de tipo bilateral entre dos personas, el factor o agente y su principal, con el fin de reflejar en cada momento la situación deudora o acreedora de aquél con respecto a éste, quedó estancada, pues desde el primer momento cumplía satisfactoriamente su limitado objetivo, esta segunda modalidad contable, en cambio, debido a las posibilidades que su planteamiento ofrecía, evolucionó y se perfeccionó constantemente hasta alcanzar su máximo exponente: la contabilidad por partida doble.

En esta evolución, de llevar en un primer momento sólo las cuentas de los deudores y acreedores, se pasó a abrir también cuentas para reflejar la compra, venta y existencias de mercaderías, posesión de bienes muebles e inmuebles, libramiento de letras de cambio, tenencias de efectivo, etc. Al lado de estos elementos patrimoniales positivos, es decir, de los que componían el patrimonio, se abrieron también cuentas para recoger los elementos negativos o que disminuían aquél, distintos de los acreedores, como podían ser los efectos aceptados pendientes de pago y otros. Como en el sistema de Cargo y Data, cada cuenta se componía de dos lados, el Debe y el Haber, sólo que ahora los dos lados se enfrentaban, uno a la izquierda y el otro a la derecha, y no se llevaban de forma separada, en dos partes, una después de la otra. En el Debe se anotaban las partidas que aumentaban el importe del correspondiente elemento patrimonial, mientras en el Haber se registraban las disminuciones. El saldo, deudor, de las cuentas correspondientes a los elementos patrimoniales positivos, es decir, la diferencia entre las sumas de su Debe y de su Haber, reflejaba en todo momento el importe del elemento patrimonial poseído. Por el contrario, el saldo, acreedor, de las cuentas correspondientes a elementos negativos suponía la disminución que debido a este elemento experimentaba el patrimonio neto del dueño de los libros. El patrimonio total de éste estaba constituido, así, por la suma de los saldos deudores correspondientes a las cuentas o elementos positivos, o de Activo, menos la suma de los saldos acreedores de los elementos negativos, o de Pasivo. Debe indicarse que la ampliación indicada de los elementos patrimoniales tomados en consideración a efectos contables se llevó a cabo, al principio, con un criterio fuertemente personificador. Así, en lugar de denominar cuenta de Mercaderías a la cuenta que recogía esta parte del patrimonio, se la llamó por el nombre 
de la persona a la que se encargaba y hacía responsable de su custodia. De igual manera, en vez de llamar cuenta de Caja a la que reflejaba el efectivo en poder del dueño de los libros, se la denominó por el nombre del cajero o persona a la que se hubiera confiado su cuidado. Esto está en consonancia con el hecho de que las primeras cuentas llevadas se abrieran a personas, deudores y acreedores.

En los años y siglos sucesivos se siguió avanzando en el perfeccionamiento de los planteamientos contables: progresó la desagregación del patrimonio en sus diversos elementos, se despersonificaron las cuentas, se separó contablemente el negocio, la empresa o la unidad económica en general de su propietario, de forma que las terceras personas no trataban ya directamente, a efectos contables, con el dueño de los libros, sino con los elementos de su patrimonio, se completó el llamado Libro Mayor, donde se llevaban las cuentas clasificadas por sus titulares, con otro libro, llamado Manual o Diario, donde se registraban previamente las operaciones por orden cronológico con indicación de las cuentas que intervenían en cada partida y su interrelación, con su carácter deudor o acreedor, etc.

Pero, pese a todos estos adelantos y progresos, no exentos, por supuesto, de retrocesos y de ensayos fracasados, la contabilidad no pegó el salto definitivo y no alcanzó su mayoría de edad hasta que se descubrió el sistema de partida doble.

DOBLE

\section{LA CONTABILIDAD MODERNA: EL SISTEMA DE PARTIDA}

Se asume con generalidad, a partir sobre todo de las explicaciones y afirmaciones de Federigo Melis y Raymond de Roover que la contabilidad por partida doble, que es el sistema contable que todavía hoy, en los tiempos de la tecnología informática, se utiliza como método insustituible, gozando de la misma lozanía que en sus mejores tiempos, fue concebida a finales del siglo XIII, como eslabón final del desarrollo de las diferentes técnicas dedicadas a satisfacer las necesidades de registro económico y financiero.

En tal sentido, la contabilidad por partida doble constituye un conjunto completo y redondo de registros, totalmente interrelacionados entre sí, que ofrecen una visión global y, al mismo tiempo, tan detallada como se quiera, de la empresa, en la que pueden hallar acomodo, en su 
debido sitio, todas las operaciones y transacciones realizadas por la misma, sin que falte una sola de ellas, por pequeña o insignificante que pueda parecer.

Antes de llegar a esta visión completa ofrecida por la partida doble se había llegado ya, como hemos visto, a una contabilidad que distinguía pormenorizadamente los elementos integrantes del patrimonio del dueño de los libros, de manera que podía saberse en todo momento el importe y la composición del mismo. Con todo, en este desarrollo avanzado de la partida simple -llamando partida simple a todos los esquemas contables anteriores a la partida doble- se echaba en falta una dimensión extremadamente útil e importante: el registro de forma directa, como un producto más de la contabilización cotidiana y habitual, de las variaciones en el importe total del patrimonio, es decir, el aumento o la disminución experimentados por el mismo como consecuencia de las ganancias o pérdidas producidas en el movimiento y empleo de los elementos patrimoniales.

El salto desde las fórmulas más perfectas y evolucionadas de la partida simple hasta la partida doble constituyó una auténtica revolución conceptual, un cambio de filosofía, que surgió posiblemente de forma espontánea, cuando los tiempos estuvieron maduros para ello, como consecuencia de las necesidades de información y control sentidas por los dueños de los libros. Ya se ha visto cómo la suma algebraica de las cuentas de un empresario, es decir, la suma de los elementos positivos menos la suma de los elementos negativos de su patrimonio, expresaba el importe neto del mismo. Pero no había ninguna cuenta que reflejara esta cifra y que recogiera sus variaciones. La idea de la partida doble nació precisamente cuando a alguien se le ocurrió enfrentar el concepto global de patrimonio al conjunto desglosado de elementos patrimoniales concretos, que era lo único que se había tomado en consideración hasta entonces. Como consecuencia de esta idea, se llevaron a un lado, el Debe o Activo, todos los elementos positivos y negativos de que se componía el patrimonio, cada cual con su correspondiente signo, mientras que en el otro, el Haber o Pasivo, se consignó un nueva cuenta totalizando el importe global de dicho patrimonio, con la denominación de Capital con que habitualmente se la conoce hoy. De este modo, la contabilidad de una empresa se convirtió en una ecuación, en la que la suma algebraica de los elementos patrimoniales constituye el primer término, que es igual al segundo, compuesto por la cuenta de Capital, cuenta que naturalmente puede desglosarse en varias, dando lugar al grupo generalmente denominado 
de cuentas de neto, es decir, la de Capital más las cuentas diferenciales. Obviamente, en esta ecuación los elementos del primer término con signo negativo pueden transferirse al segundo con signo positivo, que es lo que se hace normalmente al establecer los balances o estados financieros. Pero no debe olvidarse nunca que la naturaleza de estos elementos transferidos es inversa a la cuenta de Capital: un aumento en su saldo refleja una disminución neta en el patrimonio del dueño de los libros, mientras un aumento en la cuenta de Capital o sus desgloses significa un aumento de dicho patrimonio.

La formulación deliberada de esta comparación, de este enfrentamiento: por una parte, los elementos patrimoniales individualizados, uno a uno; por la otra, el patrimonio, considerado en su concepto global de sustancia de la empresa, como decía Pacioli, citando a Aristóteles: "luxta illud phy unum aliquid necessarium est substantia (ya lo dijo el Filósofo: sólo una cosa es necesaria: la sustancia)" (Pacioli 1494: 199 $r^{\circ}$ ), es decir, la confrontación de las partes frente al todo, superó completamente e hizo olvidar el antiguo concepto inicial de la contabilidad como registro aislado de las cantidades que nos adeudaban y que adeudábamos, extendido más tarde, sin saber muy bien por qué, a los otros elementos patrimoniales. Ahora, la contabilidad se presentaba ya como una representación global de la empresa y de su marcha, en la que cualquier anotación se integraba en el conjunto y cobraba sentido en función de su interrelación con las demás. Por simple y obvia que hoy nos pueda parecer esta visión, lo cierto es que en su momento fue la piedra filosofal de la nueva contabilidad. Merced a ella, todas y cada una de las operaciones y transacciones realizadas, incluidas las que suponían una ganancia, pérdida o gasto, pudieron ser concebidas y registradas como una relación entre dos cuentas, una en el papel de deudora y otra actuando como acreedora, de forma que la ecuación se mantenía siempre, con las ventajas operativas que lleva aparejadas a efectos de comprobación y plenitud. De ahí le viene, precisamente, al sistema el nombre de partida doble: todas y cada una de las operaciones de la firma podían ser registradas en una partida que comprendía dos cuentas, una en el Debe y otra en el Haber, por lo que debían asentarse dos veces, una en cada lado, reflejando tanto los cambios de estructura del patrimonio como las variaciones en el montante global de éste.

El carácter completo y omnicomprensivo de la contabilidad por partida doble hizo que cobraran sentido medidas adicionales para garantizar la fiabilidad de los libros. Así, se constituyó en norma 
consuetudinaria y aun legal, en algunos casos, el hecho de que los libros Diario y Mayor estuvieran encuadernados, no contuvieran tachaduras, no se dejaran hojas ni espacios en blanco, etc., todo ello al objeto de que no pudieran introducirse hojas nuevas ni sustituirse las originales, ni tampoco pudieran anularse partidas anteriores o intercalarse asientos nuevos. Asimismo, se generalizó la práctica de autenticar los libros en los Consulados $u$ otras organizaciones de mercaderes. De este modo, los libros de cuentas cobraron fuerza probatoria ante los tribunales de justicia. Los libros fundamentales a estos efectos eran el Diario y el Mayor, únicos necesarios y suficientes para llevar las cuentas por partida doble, aunque se emplearon también otros libros auxiliares, como el Borrador, el libro de Caja, el libro de Almacén, etc., con estos u otros nombres.

5. REFLEXIONES SOBRE LA ESENCIA Y NATURALEZA DE LA PARTIDA DOBLE

A la luz de todo lo explicado, se puede ya pasar a exponer las reflexiones que motivan este trabajo.

En primer lugar, me parece que para poder comprender y definir la contabilidad por partida doble sería conveniente tratar de sistematizar su naturaleza, separando lo que constituye propiamente su concepto y su filosofía, de lo que corresponde a la instrumentación del método y de lo que supone simplemente un conjunto de requisitos y prácticas formales. Como se decía más arriba, hasta ahora se acostumbra a presentar la naturaleza y las condiciones de la partida doble de forma revuelta, lo que ciertamente no parece que pueda contribuir a la clarificación de las cosas.

Siguiendo esta idea, presentaré mis reflexiones estructuradas en los tres apartados indicados: 1. Concepto de la contabilidad por partida doble; 2. Instrumentación de la partida doble; y 3. Requisitos y prácticas formales asociados a la misma.

\section{Concepto de la contabilidad por partida doble}

Por lo que se refiere al concepto, parece que lo más característico de la partida doble es, efectivamente, el hecho de que cada operación deba ser asentada en el Debe y en el Haber por el mismo importe. Pero, como, según hemos visto decía Raymond de Roover, este 
concepto no nace de una convención, sino de la propia naturaleza de los hechos, no ya del comercio, como afirmaba él, sino en general: por cada cosa que se entrega, se recibe algo a cambio, sea material o inmaterial. En consecuencia, este concepto es consustancial a cualquier operación mercantil y no pudo ser ignorado por los contables ni siquiera en los tiempos más antiguos. Los romanos conocían ya los conceptos enfrentados de Entradas y Salidas, origen de los actuales Debe y Haber. De este modo, llevaban un libro, el Codex Accepti et Expensi, que en un principio servía de una especie de Libro de Caja donde anotaban los ingresos en la columna Acceptum y en la otra columna, Expensum, los gastos. Posteriormente, este Codex Accepti et Expensi amplió su cometido, pues en él se anotaron, por mutua convención, los créditos contra los deudores del dueño del Codex. De esta práctica de formalizar por escrito, en un libro, las deudas, los compromisos, surgieron precisamente los Contratos Litteris.

Lo que importa, pues, a nuestro objeto, más que la percepción del concepto de la dualidad de anotaciones en sí por parte de los contables, que es obvia, es saber si se hizo empleo de este concepto a efectos contables, y en este caso, de qué manera y con qué amplitud.

Es sabido que en algunas contabilidades de la Baja Edad Media, aun percibiéndose claramente el concepto de dualidad, el dueño de los libros era parte integrante del juego, por lo que las operaciones en las que él resultaba afectado, su parte no era contabilizada. Por ello, las anotaciones contables que recogían estas operaciones no generaban asientos en los dos lados, Debe y Haber, sino solamente en uno de ellos. Casos típicos de estas contabilizaciones son los referidos, por ejemplo, a las compras o ventas de mercaderías en efectivo, en las que sólo se asienta el Debe o el Haber respectivamente de la cuenta de Mercaderías, con una explicación de este estilo: "Por tantas mercaderías que le he comprado o vendido a Fulano y le he pagado o cobrado de contado". La cuenta de Caja no se utiliza, aunque la contraprestación en dinero generada por el cambio de propiedad de la mercancía sea claramente percibida. Lo mismo ocurre, en ocasiones, con la entrega de dinero en pago de una deuda, que aunque se muevan las cuentas del deudor o del acreedor, la cuenta de Caja, en cambio, no se mueve; tal vez, ni siquiera exista.

Por otra parte, mientras las cuentas de neto no son creadas e introducidas en la contabilidad, la percepción de la dualidad de los asientos contables, aun pudiendo ser perfecta para las cuentas que recogen los elementos patrimoniales, no tiene un alcance completo. La introducción de las cuentas de neto en el juego contable, como reconocen prácticamente 
todos los estudiosos que se han preocupado de la cuestión según hemos visto, es, pues, lo que confiere a la partida doble su esencia, su verdadera naturaleza. Representa un salto conceptual decisivo, como se ha comentado. Antes de esta introducción, la contabilidad, aun con pleno uso de la dualidad de cuentas, sólo podía y pretendía reflejar los cambios de estructura patrimonial. Disminuían las mercancías, valga el ejemplo, y aumentaba por igual importe el dinero poseído en efectivo. Menguaba el dinero poseído, pero también disminuía el importe de las deudas pendientes de pago; el importe global del patrimonio seguía siendo el mismo. Las variaciones en el montante total del patrimonio como consecuencia de la actividad de la empresa sólo podían averiguarse una vez cerrados los libros, sacado el balance y hecho el inventario.

Dicho sea de paso, la posibilidad de establecer balances nace precisamente de este concepto de dualidad, aunque no tenga un alcance completo como consecuencia de la no incorporación de las cuentas de neto. Como veremos más adelante, el establecimiento de balances tuvo consecuencias prácticas importantes, que fueron muy valoradas en su momento.

La introducción de las cuentas de neto supuso una ampliación sustancial de horizontes, una revolución conceptual. La contabilidad ya no solamente se limitaría a registrar y proporcionar información corriente sobre la estructura del patrimonio, es decir, sobre su composición y distribución entre los diversos elementos que lo conforman, sino que también informaría corrientemente de las variaciones de su montante total, es decir, de la sustancia. Recordaremos, de pasada, que de entre los componentes de esta sustancia o patrimonio, a Pacioli le parecía que el principal era "el dinero en efectivo (pecunia numerata) o cualquier otro bien patrimonial reducible a dinero, pues sin dinero o medios de pago difícilmente se puede negociar" (Pacioli 1494: 199 r $^{\circ}$ ).

Con la incorporación de las cuentas de neto o de la segunda serie, como las llaman los italianos, el método contable es capaz de registrar cualquier operación que la unidad económica realice y con ello se convierte en el método contable por antonomasia, la partida doble, en el que todas las partidas y las cuentas se registran de forma coordinada y armónica, con expresión de las relaciones que se establecen entre ellas, formando un todo global y cerrado, donde nada queda excluido ni aislado. 
No es tanto, pues, el concepto de dualidad lo que importa, como ya se indicaba, como la aplicación que se hace de él y el alcance que se le da.

Al respecto de una contabilidad omnicomprensiva, que constituya un todo global y completo, se plantea, por otra parte, la cuestión de si una contabilidad que no contenga más que las cuentas operativas del negocio de un mercader, sin incluir sus propiedades privadas, mobiliario, etc., puede ser considerada como de partida doble. Tal circunstancia no supone un hecho hipotético e irreal, interesante sólo como un ejercicio académico. Como comenta Carlo Antinori, en Italia había la costumbre de no incluir inmuebles, fincas y demás bienes de este tipo en la contabilidad, pues según dice eran bienes cuyo valor se consideraba inalterable (Antinori 2005: 13) ${ }^{1}$. En España era también habitual en algunas ocasiones que los mercaderes no incluyeran estos bienes en su contabilidad, de forma que algún autor ha considerado este hecho como una singularidad de la partida doble española.

Algunos autores consideran a este respecto que el hecho de que una contabilidad no utilice un juego completo de cuentas la descalifica para ser considerada como partida doble. A mi entender, el hecho de que una contabilidad no contemple más que las cuentas propiamente operativas de un negocio o actividad no supone un impedimento para que pueda ser considerada como partida doble, siempre que se utilicen de la forma adecuada todas las cuentas necesarias para reflejar la situación y marcha de este negocio o actividad. Por supuesto, mejor y más completo sería incluir en la contabilidad todos los elementos patrimoniales poseídos por el dueño de los libros, como hacen Luca Pacioli y Bartolomé Salvador de Solórzano en sus ejemplos, aunque de alguna manera dichos elementos no estén involucrados en el negocio desarrollado, aunque sí, por supuesto, dado el tipo de empresa contemplada, afectos a sus resultados y respondiendo ante terceros. Incluso pienso que una contabilidad que solamente contemple una actividad concreta, como puede ser el caso del arrendamiento del abastecimiento

En efecto, con referencia a los Libros Mayores farnesianos de la contabilidad pública de Parma dice así Carlo Antinori: "El sistema contable es parcialmente completo y permite la plena aplicación de la partida doble. A un sistema contable se le llama 'parcial' cuando se refiere solamente a una parte de los bienes que componen el patrimonio de una hacienda pública o privada. Por ejemplo, los inmuebles (terrenos, construcciones rurales, palacios, etc.) no se incluían nunca en la contabilidad porque se consideraba que eran valores invariables en el tiempo". 
de carne en Burgos el ejercicio 1536-1537 (Hernández 1992) o de la operación municipal de compra de cereales llevada a cabo en 1540 por el Ayuntamiento de Medina de Rioseco (Hernández 1987), si se llevan todas las cuentas necesarias para el registro de las operaciones y se cumplen las demás condiciones de la partida doble, debe ser considerada como llevada por este método.

Con respecto a la visión limitada a la contabilidad mercantil con que Raymond de Roover enfoca la partida doble, está claramente desfasada y fuera de lugar. Yo también tuve al principio de mis investigaciones sobre la materia la tentación de identificar la partida doble como la contabilidad de los mercaderes. Pero parece claro que, si bien, la partida doble tuvo su origen en las casas de comercio, rápidamente trascendió a otros predios bien lejanos. Véanse las investigaciones de Susana Villaluenga (2004), donde se muestra cómo ya en los años 1533 y 1535 se usó la contabilidad por partida doble para llevar libros de cuentas en la Catedral de Toledo, o la obra de Angelo Pietra (1586), dedicada a explicar la contabilidad por partida doble a llevar por un monasterio benedictino, o la de Bartolomé Salvador de Solórzano (1590), que consagra un capítulo a exponer la contabilidad por partida doble que le conviene llevar a un terrateniente o una casa señorial.

\section{Instrumentación de la partida doble}

La contabilidad por partida doble no es sólo un concepto, una idea, sino también un procedimiento. Por esto no es indiferente su instrumentación a la hora de querer conocer y definir su naturaleza.

Recuerdo que de esto hablábamos Carlo Antinori y yo, hace ya algunos años, sentados cómodamente en la biblioteca de su casa de Parma, rodeados de incunables y libros valiosos, entre los que se contaban sendos ejemplares de la primera y la segunda edición de la Summa de Arithmetica, Geometria, Proportioni et Proportionalita, así como de la De Divina Proportioni, las dos obras cumbres de Luca Pacioli. Porque, como todos los historiadores de la contabilidad saben, Carlo Antinori, aparte de ser uno de los grandes patriarcas de la historia de la contabilidad a nivel mundial, es un gran bibliófilo y su biblioteca es una de las más importantes bibliotecas privadas que hoy día existen sobre esta materia.

Conversando amigablemente, me empezó a relatar Carlo la agria polémica que sostuvo con Federigo Melis a propósito de los orígenes 
de la partida doble. Sostenía Melis, en línea con su tesis ya apuntada, que lo importante para la existencia de la dualidad de anotaciones era que cada partida del Libro Mayor tuviese su contrapartida. Antinori estaba obviamente de acuerdo con esta afirmación, pero opinaba que el asiento de contrapartida debía estar anotado el mismo día y llevar la misma fecha que la partida; en caso contrario no creía que pudiera considerarse que la contabilidad en cuestión fuera llevada por partida doble, ya que en tal caso la suma total del Debe no coincidiría en todo momento con la del Haber, requisito que estimaba consustancial al método. Melis, por el contrario, se obcecaba en afirmar que el desfase de unos días no tenía importancia.

En un primer momento no comprendí bien lo que habían estado discutiendo Federigo Melis y Carlo Antinori, y pregunté cómo era posible que los dos asientos del Libro Mayor pudieran llevar distinta fecha: ¿es que no se asentaban con la fecha en que estaban anotados en el Libro Diario, con independencia del día en que se pasaran al Mayor? La respuesta de Carlo Antinori me dejó aún más sorprendido. "Ten en cuenta", me dijo,

que estábamos hablando de los comienzos de la partida doble y que el primer Libro Diario que conocemos es el de Andrea Barbarigo, que data del 2 de enero de 1430. En la época de la que hablamos posiblemente no existieran Diarios.

Esta contestación ya me sumió en total confusión:

¿Pero, cómo es posible que siempre se esté afirmando que la partida doble surgió en algún momento del siglo XIII y que la primera contabilidad de la que existe certeza que fue llevada por este sistema es la de los Massari de Génova del año 1340, cuando no se ha encontrado ningún Libro Diario de esa época?.

"Es que la partida doble es un concepto, una idea", contestó Antinori, "y esa idea se cumple pudiendo comprobar en el Libro Mayor que a cada débito le corresponde un crédito". Tuve que responderle que no estaba de acuerdo, que la contabilidad por partida doble es una idea, un concepto, sí, pero no una idea abstracta, en el aire, sino una idea instrumentada, una idea hecha realidad. $Y$ para mí, esta realidad se instrumentaba básicamente por medio de dos libros, el Diario y el Mayor. Para mí, el Libro Diario es, precisamente, el hallazgo fundamental de la partida doble, un libro por orden cronológico, donde se registran las operaciones 
con enunciación de las cuentas implicadas, la relación que se establece entre ellas y los detalles completos de la operación. Sin Libro Diario no puede haber partida doble.

Ciertamente, yo sabía que el primer Libro Diario conocido era el de Andrea Barbarigo iniciado el 2 de enero de 1430. Muchos autores hacen referencia a este hecho. Raymond de Roover mismo lo indica en su trabajo citado (1937: 277). Pero, en general, no se relaciona esta circunstancia con los orígenes de la partida doble. Se cita el hecho de pasada, como cosa aparte, independiente, como curiosidad histórica. Por otra parte, es muy distinto que se hable de los orígenes de la contabilidad por partida doble en ausencia de Libros Diario por no haber sido éstos eventualmente localizados, a que se haga a sabiendas de que no hay indicios razonables de que existan, sino más bien todo lo contrario. Así se lo hice notar a Carlo Antinori quien pareció sorprendido, seguramente nunca se había hecho esta reflexión, como me había ocurrido a mí hasta que se puso bruscamente ante mis ojos la incongruencia de hablar de partida doble sin Libros Diario. Después de una larga y amistosa discusión, Carlo tuvo que darme la razón, al menos en parte. Fruto de este reconocimiento es la nueva actitud que ha adoptado ante el Libro Diario al hablar del origen de la partida doble, actitud que se refleja en las siguientes palabras:

Si las contabilidades antiguas, me refiero a las de los siglos XIII y XIV, hubieran previsto también el Libro Diario, estos problemas interpretativos (acerca de la naturaleza de la partida doble, se entiende) no hubieran surgido. Por esta razón, hablaré más adelante del Diario como de un libro de suma importancia, muy superior a la que los historiadores referidos (Fabio Besta, Federigo Melis y Tommaso Zerbi) han querido reconocerle. El ejemplar más antiguo que ha llegado hasta nosotros es el de Andrea Barbarigo y lleva la fecha del 2 de enero de 1430, aunque en realidad correspondería al año 1431, pues según la costumbre veneciana el año comenzaba el $1^{\circ}$ de marzo, es decir, tres meses después del $1^{\circ}$ de enero (Antinori 2001: 3).

De otro lado, la noción de que la partida doble es sólo un concepto, una idea, no es sostenible en absoluto. ¿Qué idea? ¿La de que cada cosa que alguien recibe implica necesariamente alguien que la entrega?... Ya hemos visto los condicionantes necesarios para que la aplicación práctica de esta idea pueda dar lugar a un método en sí y de por sí. 
En cualquier caso, lo cierto es que existen graves incoherencias y contradicciones internas a este respecto entre los autores. De forma más o menos explícita, casi todos aceptan que el modelo pacioliano refleja la quintaesencia de la contabilidad por partida doble. Pues bien, Pacioli en su capítulo V habla de tres libros principales para llevar la contabilidad:

Deberás abrir tres libros que te serán necesarios para tu comodidad y buen orden: uno llamado Borrador, otro llamado Diario y otro llamado Mayor, aunque algunos comerciantes, dado el escaso volumen de sus negocios, emplean sólo dos, el Diario y el Mayor.

Como se ve, el Borrador no lo considera indispensable. De igual manera, se viene aceptando generalmente por los investigadores que el Libro Diario es el más importante entre los libros, porque es el que sirve de prueba en caso de juicio y porque merced a él, en caso de extravío o destrucción, se puede reproducir el Libro Mayor sin gran dificultad. Sin embargo, a la hora de investigar acerca de los orígenes de la partida doble, se avienen a aceptar la posibilidad de la misma sin la existencia del Diario, bien porque no reparan en la incongruencia que esto supone, bien porque no se percatan de que la falta de Libros Diarios anteriores pueda ser debida a que tales libros no eran llevados, y no, simplemente, a que no haya sobrevivido ninguno, o a que habiendo sobrevivido, no hayan sido encontrados. Sea como fuere, la incoherencia de aceptar, por un lado, las reglas de Pacioli como definitorias de la partida doble y de aceptar, por el otro, como partida doble contabilidades que no llevaban Libros Diario parece obvia.

Por todo ello, parece claro que la cuestión del origen de la contabilidad por partida doble merece una revisión, así como una reflexión profunda sobre el hecho de si realmente puede aceptarse como partida doble una contabilidad que no lleve ni se proponga la llevanza de Libros Diario.

Otra cuestión que cae dentro del sector de instrumentación es el referido a la disposición de las cuentas de Mayor en secciones contrapuestas. Lo mismo cabe decir de la enunciación en los asientos del Diario de las cuentas involucradas, con indicación mediante fórmulas convenidas de su carácter deudor o acreedor, del empleo de una única moneda de cuenta en las columnas de cantidades de los libros, de la indicación de la fecha en cada asiento, de la simultaneidad de las fechas de anotación de los asientos en los libros y en las cuentas deudoras y acreedoras en el Mayor, de la suma del Debe y Haber de las cuentas del 
Libro Mayor -la suma de la columna de cantidades de las páginas del Diario era considerada una pérdida de tiempo en la época inicial de la partida doble-, de la indicación en el margen derecho del Diario de los folios en el Mayor de las cuentas implicadas, el de la deudora encima y el de la acreedora debajo, de la indicación del folio de la cuenta de contrapartida en los asientos del Mayor -la indicación del número del folio del Diario era considerada superflua, ya que la fecha constituía suficiente orientación-, y de la paginación de los folios de los libros.

Otras cuestiones que pueden considerarse incluidas en este apartado de la instrumentación de la partida doble son, siguiendo a Pacioli, la del Inventario inicial, al comienzo de las actividades de la empresa o unidad económica, la del Balance de fin de ejercicio, después de haber hecho los asientos de regularización, el traspaso de los saldos de las cuentas del libro viejo al libro nuevo, etc. Como es sabido, Pacioli no preveía asientos de cierre o apertura en el Diario, sino el traspaso directo de los saldos del Mayor viejo al Mayor nuevo. Pienso que todas estas cuestiones, aun pareciendo de menor relevancia, son también importantes a la hora de calificar la contabilidad como de partida doble, sobre todo la de la regularización de las cuentas y la del balance cuyo cuadre servía como de medio de comprobación de que las cantidades habían sido correctamente inscritas en el Libro Mayor. Este hecho fue de mucha importancia y contribuyó grandemente al prestigio de la contabilidad por partida doble, pues uno de los problemas más serios de los métodos contables anteriores era la dificultad para detectar los errores.

La falta de alguna de estas condiciones de procedimiento puede que, por sí sola, no fuera suficiente para invalidar la calificación de partida doble de la contabilidad donde se produjera, pero en cualquier caso la limitaría y debería hacerse mención expresa de ella.

\section{Requisitos y prácticas formales de la partida doble}

Como se ha señalado más arriba, al tener la contabilidad por partida doble un carácter completo, global y cerrado, cobraron sentido medidas adicionales para garantizar la fiabilidad de los libros. De esta forma, se estableció que los libros Diario y Mayor debían estar encuadernados, al objeto de que no pudieran intercalarse folios nuevos ni retirarse los originales con el fin de impedir la introducción de asientos nuevos o la desaparición de partidas anteriores. Por otra parte, no debían dejarse folios ni espacios en blanco, de forma que no pudieran introducirse 
anotaciones falseando la secuencia temporal. Los espacios en blanco que quedaran en alguno o ambos lados de las cuentas del Libro Mayor por traspaso o cierre de las mismas, debían anularse, haciéndolos inutilizables. No podían producirse tachaduras. Los errores y equivocaciones debían salvarse de forma que el error quedara siempre patente. Si, por ejemplo, se había pasado un asiento a una cuenta de Mayor equivocada o a un lado erróneo, se debería corregir el error mediante un contraasiento en el lado opuesto, explicando el motivo. Si el error hubiera sido en el texto o en algún número en la columna de cantidades, lo mismo en el Diario que en el Mayor, se tendría que corregir asimismo mediante la oportuna explicación o en su caso anulación por contraasiento. Lo importante era que el error cometido fuera siempre reconocible, aunque sus efectos se hubieran cancelado.

De esta manera, los libros de cuentas por partida doble y, sobre todo, el Libro Diario, cobraron capacidad de prueba en los juicios. Bien es cierto que, normalmente, esta capacidad no era en favor del dueño de los libros, sino en su contra. El peligro estribaba, pues, en que la parte litigante contraria exigiese la presentación de los libros de cuentas de la otra parte y, si éstos no estaban llevados de forma correcta, ejercieran prueba en contra de su dueño. He examinado esta problemática, muy interesante, en un par de trabajos (Hernández 1997 y 2000).

A mi entender, la falta de alguno de los requisitos formales que hemos enunciado, aunque pudiera afectar a la capacidad probativa de los libros, no debería menguar normalmente su condición contable de partida doble. Debería, sin embargo, hacerse mención de ella.

\section{CONCLUSIONES}

En este trabajo he intentado reflejar algunas preocupaciones personales en relación con la naturaleza y los orígenes de la contabilidad por partida doble. Se trata obviamente de reflexiones y opiniones subjetivas, que en su conjunto expresan el convencimiento de que sería conveniente retomar esta cuestión y proceder a una reconsideración de la misma con el objeto de revisar algunos de sus postulados y, sobre todo, el tema de la fecha de la aparición de la partida doble. No se me oculta la seria dificultad de que los estudiosos de la materia se avengan a revisar y, eventualmente, a modificar algunas de las nociones vigentes durante tantos años, pero, sea lo que fuere, creo que existe una evidente necesidad de clarificar y conciliar algunos puntos a este respecto. 
En tanto se llega a esta reconsideración, me permito finalmente resumir, de forma provisional y sin ánimo de exhaustividad, las principales condiciones que a mi juicio definen y caracterizan la naturaleza y la práctica de la contabilidad por partida doble, agrupadas en los tres apartados ya señalados:

\section{Concepto}

1. Consideración de las operaciones en un doble aspecto que viene dado por la misma realidad de los hechos: toda entrada en una cuenta implica una salida en otra.

2. Consiguiente dualidad de las anotaciones: todo asiento en el Debe requiere un asiento en el Haber por igual importe. De este modo, las sumas totales del Debe tienen que ser iguales a las del Haber.

3. Presencia de un juego completo de cuentas: cuentas de personas, de valores, de gastos, de resultados y de capital. Es decir, cuentas de elementos patrimoniales y cuentas de neto o, siguiendo la terminología italiana, cuentas antitéticas de la primera y de la segunda serie.

4. De esta manera, merced a este juego completo de cuentas, todas las operaciones realizadas por el dueño de los libros son susceptibles de contabilización y la contabilidad está en situación de reflejar tanto los cambios de estructura del patrimonio como las variaciones en su montante o valor.

5. Cuando la contabilidad no abarca la marcha de un negocio completo, sino solamente una actividad singular o un conjunto de operaciones concretas no es necesario el empleo de todo el juego de cuentas. Bastará con que se utilicen las cuentas necesarias para contabilizar debidamente la actividad o las operaciones de que se trate.

6. Por otra parte, la no inclusión de las cuentas de inmuebles o mobiliario en la contabilidad de un negocio no justifica la descalificación de dicha contabilidad como de partida doble. Ello era una práctica habitual en la partida doble en sus primeros tiempos.

7. El dueño de los libros no tiene que intervenir directamente en el juego contable. Son las cuentas de sus elementos patrimoniales y sus cuentas de neto las que se mueven y relacionan entre sí. 


\section{Instrumentación}

8. Empleo de dos libros principales: Libro Diario y Libro Mayor; el primero entendido como un libro de secuencia cronológica, con inscripción y explicación de las operaciones, así como con la indicación y el signo de las cuentas que intervienen en las mismas. El segundo, como libro clasificado por cuentas, derivado y tributario del primero, en el puede encontrarse de inmediato el movimiento y la situación de cada cuenta.

9. Utilización de una moneda de cuenta única en las columnas de cantidades.

10. El Libro Mayor debe ser llevado en secciones contrapuestas.

11. Indicación en los asientos de sus correspondientes fechas.

12. Simultaneidad de las fechas con que son anotados los asientos en el Diario y en el Debe y Haber del Mayor.

13. Suma de las columnas del Debe y el Haber en el Libro Mayor.

14. Indicación de los folios de las correspondientes cuentas del Libro Mayor en los asientos del Diario.

15. Indicación de los folios de las correspondientes cuentas de contrapartida en los asientos del Libro Mayor.

16. Numeración de los folios del Libro Diario y del Libro Mayor.

17. Formulación de un Inventario inicial al comienzo de las operaciones, que será pasado al Libro Diario y de allí al Libro Mayor. resultados.

18. Regularización de las cuentas diferenciales y de

19. Cierre del Libro Mayor viejo con traspaso de los saldos de las cuentas al Mayor nuevo como apertura del mismo.

20. Establecimiento del Balance de fin de ejercicio.

\section{Requisitos formales}

21. Los Libros Diario y Mayor deben estar encuadernados. 
22. No deben dejarse páginas en blanco.

23. Tampoco deben dejarse espacios en blanco. Los que se dejen por cierre o traspaso de las cuentas deben ser inutilizados.

24. No pueden hacerse tachaduras.

25. Los errores que se cometan deben ser salvados mediante contraasientos o explicaciones, según los casos, pero siempre dejando evidencia de los errores cometidos.

\section{REFERENCIAS}

ANTINORI, Carlo (2001) "Orígenes de la Partida Doble". Comunicación presentada en el XI Congreso AECA, Madrid, 26-28 de septiembre.

- (2003) "Prácticas contables italianas antes de Pacioli". Conferencia en el Curso de Verano "Pacioli y el Renacimiento", Miraflores de la Sierra, Madrid, 11-13 de septiembre.

- (2005) "Contabilidades públicas estatales en Italia a finales del Medioevo y comienzos de la Edad Moderna". Comunicación presentada en el $V$ Encuentro de Trabajo de Historia de la Contabilidad: Cervantes y la Real Hacienda, Toledo, 20-22 de abril.

BESTA, Fabio (1891-1910) La Ragioneria, Venecia.

CASTILLO, Diego del (1522) Tratado de cuentas, Burgos.

COVARRUBIAS, Sebastián de (1987) Tesoro de la Lengua Castellana o Española, según la impresión de 1611, con las adiciones de Benito Remigio Noydens publicadas en la de 1674. Reimpresión de la edición facsimilar preparada por Martín de Riquer en 1943. Editorial Alta Fulla, Barcelona.

FALKENSTEIN, A. (1964) Keilschriftforschung und Alte Geschichte Vorderasiens, Leiden: E. J. Brill.

HERNÁNDEZ ESTEVE, Esteban (1987) "Una operación municipal de compra de cereales. Libros de caja y manual de compra del pan del Ayuntamiento de Medina de Rioseco (1540)", en Moneda y Crédito, núm. 181, 1987. La versión original de este trabajo, en inglés, con el título "A Municipal Purchase of Corn. Bread Ledger and Journal of the Town Council of Medina de Rioseco (1540)", fue presentada en el Fourth International Congress of Accounting Historians, Pisa, 23 a 27 de agosto de 1984. Una versión algo resumida de este trabajo está publicada en los Proceedings of the Congress, Pisa, 1984. 
- (1992) Noticia del abastecimiento de carne en la ciudad de Burgos (1536-1537). Libro Mayor del obligado de las carnicerías, Banco de España, Servicio de Estudios, Madrid.

- (1997) "Los libros de cuentas en la jurisdicción mercantil privativa. Un contable ante los Tribunales: el pleito de Gregorio French contra Antonio Matheu en el Consulado de Comercio de Barcelona, años 17641766". Trabajo presentado en el IX Congreso AECA, celebrado en Salamanca los días 25, 26 y 27 de septiembre de 1997 y publicado en las Actas del Congreso.

- (2000) Los libros de cuentas y la jurisdicción privativa mercantil en España. El caso del Consulado de Comercio de Barcelona y su Instrucción contable de 1766. Discurso de ingreso del académico correspondiente electo para Madrid en la Real Academia de Ciencias Económicas y Financieras, Barcelona.

MATTESSICH, Richard (1977) "Prehistoric accounting and the problem of representation: an archeological evidence of the Middle East from 8,000 B.C. to 3,000 B.C.", en The Accounting Historians Journal, vol. 14 , núm. 2.

- (1988) "Wittgenstein and archeological evidence of representation and data processing from 8000 B.C. to 3000 B.C.", en Ota Weinberger, P. Koller and A. Schramm (eds.): Philosophy of Law, Politics and Society, Hölder, Pichler-Tempsky.

- (1994) "Archeology of accounting and Schmandt-Besserat's contribution", en Accounting, Business and Financial History, vol. 4, núm. 1.

- (1996) "Aspects of Early Accounting Systems (after 3000 B.C.) and their Relation to Our Time". Comunicación presentada en el 7th World Congress of Accounting Historians, Kingston, 11-13 agosto 1996.

MELIS, Federico (1950) Storia della Ragioneria, Bolonia: Zuffi.

- (1962) Aspetti della vita economica medievale, Siena.

NisSEn, Hans J., Peter Damerow y Robert K. ENGLUND (1990) Frühe Schrift und Techniken der Wirtschaftsverwaltung in alten Vorderen Orient: Informationsspeicherung und -verarbeitung vor 5000 Jahren, Berlín: Verlag Franz Becker. Existe traducción al inglés bajo el título: Archaic Bookkeeping. Writing and Techniques of Economic Administration in the Ancient Near East, Chicago y Londres: The University of Chicago Press, 1993.

PACIOLI, Luca (1994) De las Cuentas y las Escrituras. Título Noveno, Tratado XI de su Summa de Arithmetica, Geometria, Proportioni et Proporcionalita, Venecia 1494. Estudio introductorio, traducción y notas 
por Esteban Hernández Esteve, con una reproducción fotográfica del original, Madrid: Asociación Española de Contabilidad y Administración de Empresas (AECA).

PIETRA, Angelo: Indirizzo degli economi o sia ordinatissima instruttione da regolatamente formare qualunque scrittura in un libro doppio, Mantua, 1586.

ROOVER, Raymond de (1937) "Aux origines d'une technique intellectuelle. La formation et l'expansion de la comptabilité à partie double", en Annales d'Histoire Economique et Sociale, vol. IX.

SAlVAdOR DE SolóRzano, Bartolomé (1590) Libro de Caxa y Manuel de cuentas de Mercaderes, y otras personas, con la declaracion dellos, Madrid: Pedro Madrigal.

SCHMANDT-BESSERAT, Denise (1978) "The Earliest Precursor of Writing", en Scientific American, vol. 238, núm. 6.

- (1980) "The Envelopes that Bear the First Writing", en Technology and Culture, vol. 21, núm. 3.

- (1981a) "Tablets and Tokens: A Re-examination of the So-called 'Numerical Tablets", en Visible Language, vol. 15.

- (1981b) "Decipherment of the Earliest Tablets", en Science, vol. 211.

- (1983) "Tokens and Counting", en Biblical Archeologist, Spring.

- (1984a) "The Emergence of Recording", en American Anthropologist, vol. 84.

- (1984b) "Before Numerals", en Visible Language, vol. 15, núm. 1.

- (1986a) "The Origins of Writing - An Archeologist's Perspective" en Written Comunication, vol. 3, núm. 1, enero.

- (1986b) "The Precursor to Numerals and Writing", en Archeology, noviembre-diciembre.

- (1988) "Tokens at Uruk", en Baghdader Mittei-lungen, vol. 19.

- (1992a) Before Writing, 2 vols., Austin, Texas.

- (1992b) "Accounting at the Dawn of History". Comunicación presentada en el 6th World Congress of Accounting Historians, Kyoto.

VILLALUENGA DE GRACIA, Susana (2004) La Catedral de Toledo en la primera mitad del siglo XVI: Organización Administrativa, Rentas y Contabilidad. Tesis doctoral presentada en la Universidad de Castilla-La Mancha. 